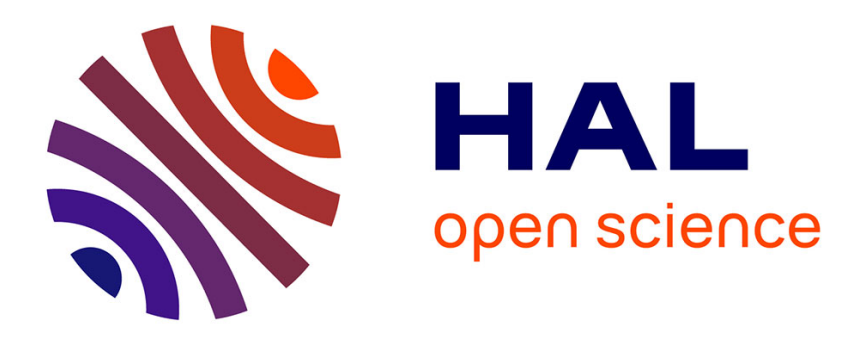

\title{
PAL study of graft polymerization of MMA on polyethylene
}

\author{
V. Sanchez, R. Lopez, Y. Ito
}

\section{To cite this version:}

V. Sanchez, R. Lopez, Y. Ito. PAL study of graft polymerization of MMA on polyethylene. Journal de Physique IV Proceedings, 1993, 03 (C4), pp.C4-287-C4-289. 10.1051/jp4:1993446 . jpa-00251489

\section{HAL Id: jpa-00251489 https://hal.science/jpa-00251489}

Submitted on 1 Jan 1993

HAL is a multi-disciplinary open access archive for the deposit and dissemination of scientific research documents, whether they are published or not. The documents may come from teaching and research institutions in France or abroad, or from public or private research centers.
L'archive ouverte pluridisciplinaire HAL, est destinée au dépôt et à la diffusion de documents scientifiques de niveau recherche, publiés ou non, émanant des établissements d'enseignement et de recherche français ou étrangers, des laboratoires publics ou privés. 


\section{PAL study of graft polymerization of MMA on polyethylene}

\section{SANCHEZ, R. LOPEZ and Y. ITO}

Instituto Nacional de Investigaciones Nucleares, A.P. 18-1027, Mexico 11801, D.F.

${ }^{*}$ Research Center for Nuclear Science and Technology, The University of Tokyo, Tokai, Ibaraki 319-11, Japan

\section{Abstract}

PAL measurements rere used to study the process of graft polymerization of methyl methacrylate (MMA) to low density polyethylene (LDPE). When the monomer was just sorbed to LDPE, both $I_{3}$ and $\tau_{3}$ were increased. When MMA was grafted to LDPE, on the other hand, they were decreased. These contrasting results suggests usefulness of the PAL method to study the micro-structures of polymers.

\section{Introduction}

PAL is important since it brings forth information about the free volume of polymers. Me have started a collaborative work of using PAL to study the structure of graft-polymerization. The first outcome was the study of vapor sorption in polymers ${ }^{(1)}$. In that paper it was shown that PAL is useful to distinguish different sorption states, i.e. Langmuir-type and Henry-type sorptions. This is mainly due to the particular nature of positronium (Ps) which reflects the size and density of the free volume holes. In this paper we present wore recent results, where sorption and grafting of methyl methacrylate (MMA) to low density polyethylene (LDPE) are compared.

Experimental

The PAL spectrometer was the standard fast-fast coincidence method. Several sheets of LDPE films were cut and stacked together with a positron source in the sandwich geometry. For the sorption experiments, this stack of polymer and source was put into a glass tube as shown in Fig.1. MMA liquid was put in the other arm of the tube, and after evacuating the whole system the stop cock connecting the both arms were opened. PAL spectra were repeatedly recorded at a regular time interval (sorption experiment). After sufficient duration of these measurements, the whole system was evacuated and PAL measurements Fere continued (desorption experiment). This desorption measurements were performed in order to confirm that we are exactly
Fig.1 The sample tube for the sorption and desorption experiments.

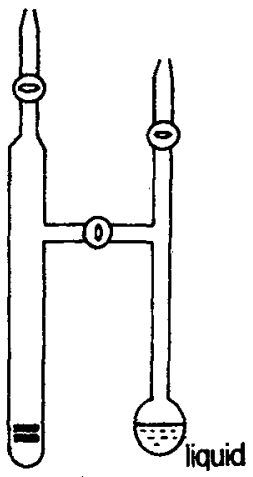

sample and positron source 
Fig. 2 Effects of sorption of MMA in LDPE
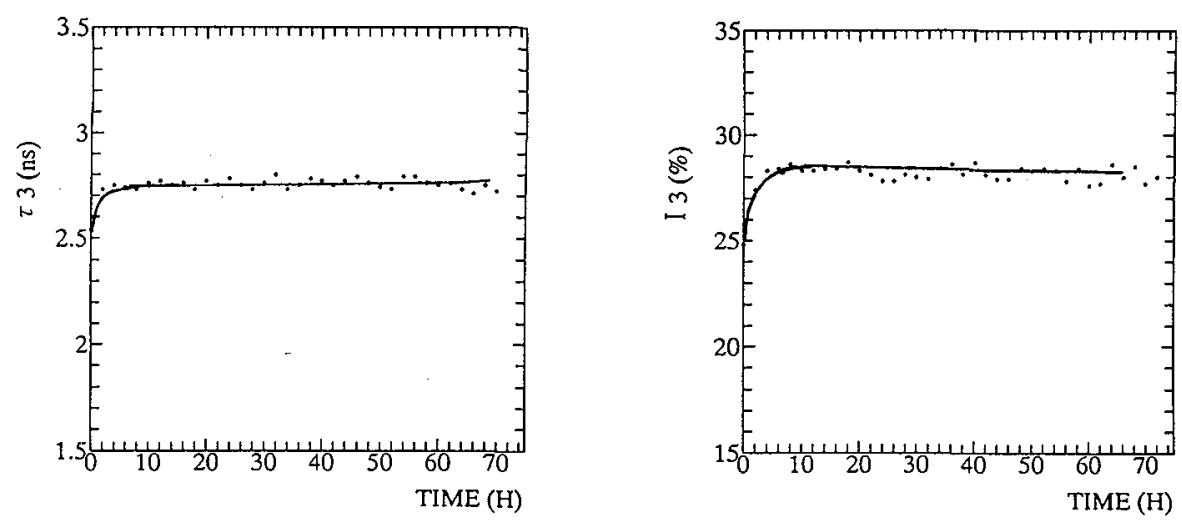

Fig. 3 Effects of desorption of MMA from LDPE
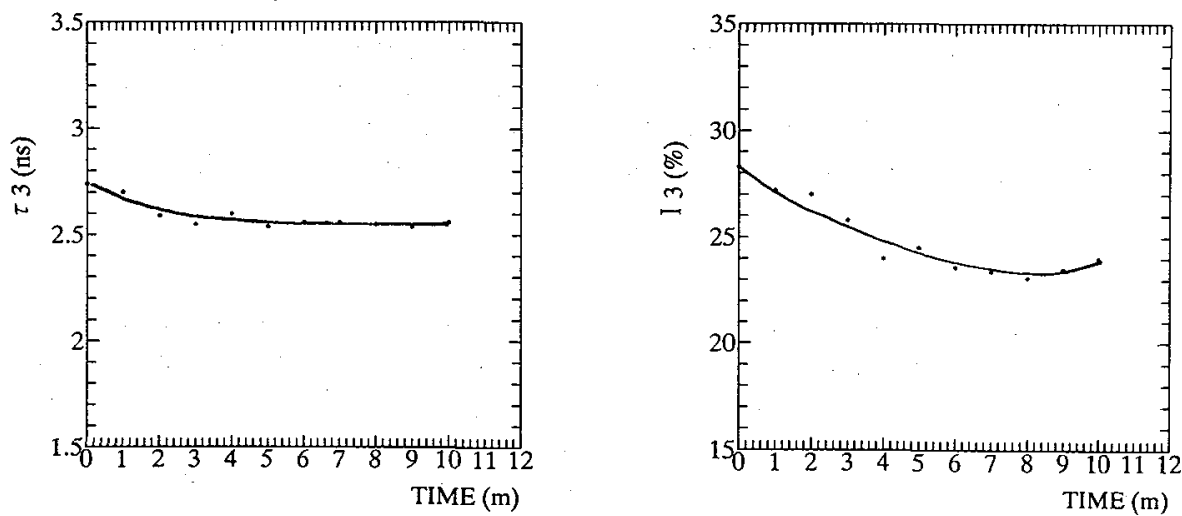

measuring the sorbed MMA, and not poly-MMA which might have formed during the sorption measurements. (Polymerization would be quite easy since the sorbed MMA vapor is very pure and is subjected to irradiation by the positron source.) For the graft-polymerization, LDPE films containing sorbed MMA were irradiated with Co-60 gamma-rays up to the dose of $150 \mathrm{krad}$. After the irradiation unreacted MMA vapor was evacuated, and the yield of graft-polymerization was determined from the increased meight. PAL spectra was measured for this grafted polymer.

\section{Results}

The data of sorption and desorption measurements are shown in Fig.2 and Fig.3, respectively. In the sorption measurements both $I_{3}$ and $\tau_{3}$ were increased. This agrees with our previous report ${ }^{(1)}$ for sorption of various kinds of vapor molecules in LDPE. According to the discussion there, the increase of $I_{3}$ and $\tau_{3}$ is due to plasticization of LDPE caused by MMA sorbed by the Henry-type sorption. In the desorption measurements both $I_{3}$ and $\tau_{3}$ are seen to restore their initial values. Thus it is concluded that the observed effects are due to the sorbed MMA and not due to poly-MMA that might have formed during the PAL measurements.

The yield of the graft polymerization is shown in Fig.4. The graft-polymers are obtained up to about $30 \%$. The variations of the o-Ps parameters are shown in Fig.5 and Fig.6. decreases with the graft yield and $I_{3}$ decreases sharply at first and then increases gradually. These changes are quite different from the case of the sorption (Fig.2). The structure of the 
free volume holes rould change substantially on formation of graft-polymers, and they most probably become smaller. Furthermore, grafting of MMA makes the LDPE chains more rigid and less plastic. Due to these effects the lifetime of o-Ps $\tau_{3}$ should become smaller. This is what has been observed (Fig.5), but in fact the decrease in $\tau_{3}$ is not very large. The results show that the size of the free volume holes is not wuch changed due to the grafting. This is probably because many free volume holes are left without being used in the process of graft-polymerization.

The change in $I_{3}$ is sharp at the initial stage where the grafting yield is small. This decrease cannot be explained by simply regarding the graft-polymer as mixture of polyethylene and poly-MMA, because $I_{3}(=26 \%)$ and $\tau_{3}(=1.92 \mathrm{~ns})$ are close to those of LDPE. Apparently the density of the free volume holes has been decreased by the grafting. The later gradual increase in $I_{3}$ implies that the polymer chains are being rearranged by substantial degree of graft-polymerization.

\section{Conclusion}

PAL has been usefully used to probe the graft-polymerization from the viempoint how the free volume holes are changed. Similar experiments are under way for other systems.

reference

1/ Ito,Y, Sanches,V, Lopez,R, Fucugauchi,L.A, Tanaka,K, and Okamoto,K; "The effects of vapor sorption in polymers obs erved by positro n annihilation", Bull. Chem. Soc. Jpn., 66(1993) 727

Fig. 4 Yield of graft-polymerization of MMA to LDPE

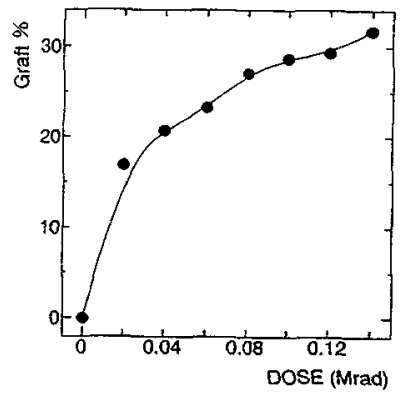

MMALDPE GRAFT COPOLYMERIZATION

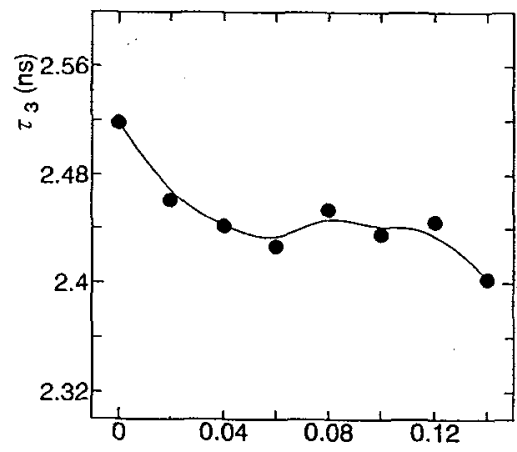

Fig. 5 DOSE (Mrad)

Change of o-Ps lifetimes due to graft-polymerization

MMALLPE GRAFT COPOLYMERIZATION

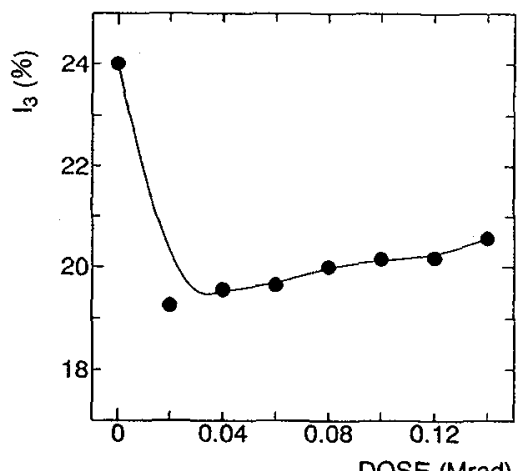

Fig.6 DOSE (Mrad)

Change of o-Ps intensity due to graft-polymerization 